\title{
Medikal Tedavi Verilen Ektopik Gebeliklerin Başlangıç B-Hcg Değeri ve 4. Gün B-Hcg Değerindeki Değişikliğe Göre Başarı Durumunu Öngörme: 183 Olgu İçeren Retrospektif Bir Çalışma
}

Prediction of Treatment Success According to First Day and Fourth Day B-Hcg Values of Ectopic Pregnancy Patients which Treated with Methotrexate: A Retrospective Study of 183 Patients

\section{Ramazan DENIZLİ ${ }^{1}$, Önder SAKİN ${ }^{2}$, Nayif ÇİÇEKLİ ${ }^{3}$, Ali Doğukan ANĞIN ${ }^{2}$ Muzaffer Seyhan ÇIKMAN ${ }^{2}$, Zehra Meltem PİRIMOĞLU ${ }^{2}$}

\author{
1. Arhavi Devlet Hastanesi, Artvin, Türkiye \\ 2. Kartal Dr. Lütfi Kırdar Eğitim Araştırma Hastanesi, Kadın Hastalıklarl ve Doğum Anabilim Dalı, Türkiye \\ 3. Varto Devlet Hastanesi, Muş, Türkiye
}

\section{$\ddot{O Z E T}$}

Amaç: Bu çalışma, medikal tedavi verilen ektopik gebeliklerde başlangıç B-hCG değeri ve 4.gün $B-h C G$ değerindeki değişikliğe göre başarı durumunu öngörmeyi amaçlamıştır.

Gereçler ve Yöntem: Çalışmada 2009-2017 yılları arasında Kartal Dr. Lütfi Kırdar Eğitim ve Araștırma Hastanesinde tek doz methotrexate ile tedavi edilen ektopik gebeler retrospektif olarak incelendi. Çalışmaya uygun 183 hasta araştırmaya alın$d l$.

Bulgular: Araştırmamızda, hastaların \%77,6'sı(142/183) ilk doz MTX ile tedavi edilirken, 2.doz MTX yapılıp başartlı olan hastalar da eklendiğinde toplam bașarı oranı \%91,8( 168/183) bulunmuştur. Başlangıç değerlerine baktığımızda ise $B-h C G<2000$ olan hastaların ilk doz MTX ile daha yüksek oranda $(\% 89,47)$ bașarll olduğu, ek doz MTX gereken hastaları da dikkate aldığımızda ise başlangıç $B-h C G<4000$ olan hastaların \%95,95'inin bașarll olduğu bulunmustur. Hastaların 4.gün B-hCG değişikliğine bakıldiğında ise \%10 ve üzerinde düsme olan hastaların \%94,6'sı basarılı olurken, \%10 altında düşme olanlarda da \%48,6 s’nda başarılı olduğu görülmüsştür.

Sonuç: Başlangıç B-hCG değeri arttıkça MTX ile başarı orani azalmasina răgmen $B-h C G>5000$ değerlerdeki hastalarda bile \%72 gibi başarı olduğu unutulmamall ve kontrendikasyon olmayan hastalarda öncelikle MTX tedavisi denenmelidir. Hastaların 4. Gün $B-h C G$ değerindeki \%10 ve üzerindeki düşme başart durumunu öngörme konusunda etkili olmasına rağmen negatif prediktif değerinin \%48,6 olması başarı durumunu öngörme konusunda dezavantajını oluşturmaktadır.

Anahtar Kelimeler: metotreksat, ektopik gebelik, diş gebelik, beta-hcg, MTX, B-hcg

\section{ABSTRACT}

Objective: We aimed to predict treatment success with comparing $B$-hcg values on first and fourth days of methotrexate injection.

Material and Methods: We research the informations of ectopic pregnancy, retrospectively, between years 2009 and 2017 in Kartal Dr.Lütfi Kirdar Training and Research Hospital which treated with single dose MTX. 183 patients included into the study.

\section{İletișim}

Sorumlu Yazar: Ramazan DENIZLI

Adres: Arhavi Devlet Hastanesi,

Artvin, Türkiye

Tel: +90 (466) 3124071

E-Posta: dr.ramazn@hotmail.com

Makale Geliș: 07.09.2018

Makale Kabul: 05.03.2019

DOI: http://dx.doi.org/10.16948/zktipb.458145
Results: In our study; 77,6\% of patients treated with single dose MTX injection. With inclusion of second dose injected patients, success rate is rising to $91,8 \%$. When we look at the prior B-hcg values, patients, those have less than $2000 \mathrm{mIU} / \mathrm{mL}$ values, have higher treatment success rate with single dose MTX injection. When we look at the patients, who needed second MTX dose, we have seen 95,95\% success rate on patients' B-hcg values less than $4000 \mathrm{mIU} / \mathrm{mL}$. More than 10 percent decrease of Patients $B$-hcg value between first and fourth days of treatment showed $94,6 \%$ success rate. As patients' treatment, whose B-hcg values decreased less than 10\%, showed 48,6\% success rate.

Conclusion: Despite treatment success rate as initial B-hcg levels rises, we have to keep in mind that even patients with higher than $5000 \mathrm{mIU} / \mathrm{mL} B-h C G$, there is a $72 \%$ treatment success rate. If there is no contraindication, still MTX treatment considered as a good choice of treatment. More than 10 percent decrease on patients' fourth day of treatment B-hcg values seems to be a good parameter for treatment success prediction. But there is $48,6 \%$ of negative predictive value, and this is a disadvantage about prediction of MTX injection treatment success.

Keywords: methotrexate, ectopic pregnancy, beta-hcg, MTX, B-hcg

\section{GíRiş}

Ektopik gebelik, fertilize olan ovumun uterin kavite dışına yerleşmesidir. Genel olarak tüm gebeliklerin \%1-2 kadarını ektopik gebelikler oluşturur. Her ne kadar geçirilmiş tubal cerrahi, infeksiyon, konjenital tuba hasarı, pelvik inflamatuvar hastalık (PIH), rahim içi araç (RİA) varlığı, geçirilmiş ektopik gebelik gibi risk faktörleri suçlansa da çoğu vakada bu risk faktörler olmayabilir (1).

Ektopik gebeliklerin çoğu fallopi tüpünde (\%84) görülür, diğer yerler ise servikal, interstisyal, histerotomi (sezaryen) skarı, intramural, ovaryan, abdominal ve heterotopik (hem uterin hem de ekstrauterin gebeliği içerir) gebelik olabilir (2). Son yıllarda yardımcı üreme tekniklerindeki artma, cinsel yolla bulaşan enfeksiyonlarda artış gibi nedenlerden dolayı ektopik gebeliğin görülme s1klığı artmıştır. Hastaların kolayca sağlık hizmetlerine ulaşabilmeleri, hemen her sağllk merkezinde B-hCG testinin bakılabiliyor olması, ultrasonlardaki çözünürlüğün artması gibi nedenlerden dolayı ektopik gebelik hastaları daha erken tanı almakta ve erken dönemde medikal tedavi verilerek komplikasyon oranlarında azalma yaşanmıştır. 
Ektopik gebelik ve buna bağl1 komplikasyonlar birinci trimestır gebeliklerde en ciddi mortalite ve morbidite nedenidir. Vajinal kanama, karın ağrısı ve adet gecikmesi klasik triadını oluşturmaktadır. En önemli tanı yöntemi B-hCG ölçümü ile transvaginal ultrasonun kombine değerlendirilmesidir. B-hCG değeri $>1500 \mathrm{mlU} / \mathrm{mL}$ iken transvaginal usg'de intrauterin gestasyonel kesenin görülmemesi durumunda ektopik gebelik akla getirilmelidir (3).

Ektopik gebelik tanısı alan hasta için ekspektan yaklaşım, methotrexate, laparoskopi veya laparotomi tedavilerinden en uygun olan yöntem seçilir. 2000'li yılların başlarına kadar daha çok cerrahi yöntemler tercih edilse de günümüzde MTX tedavisi için kontrendikasyonu olmayan hastalar yan etkilerinin düşüklüğü, yüksek başarı oranı ve uygun maliyet gibi avantajları nedeniyle MTX ile medikal tedavi daha tercih edilir olmuştur (5). MTX ile yapılan tedaviyi araştıran çalışmalarda başarı oranı \%80-90 bulunmuştur (5-11).

\section{GEREÇ ve YÖNTEM}

Kartal Dr. Lütfi Kırdar Eğitim Araştırma Hastanesinde 2009-2017 y1llarında ektopik gebelik tanis1 nedeniyle methotrexate tedavisi alan hastalar retrospektif olarak incelendi. Hastalardan alınan tüm kan örnekleri Beckman coulter Dxİ 800 marka cihaz ile B-hCG kiti ile çalışılmıştır. B-hCG değeri $<10000 \mathrm{mlU} / \mathrm{mL}$, fetal aktivitesi olmayan, ektopik odağ $1,5 \mathrm{~cm}$ boyutundan küçük, hemodinamisi stabil, aktif karaciğer, böbrek hastalığ 1 olmayan ve tek doz methotrexate protokolü tedavisi uygulanan hastalar çalışmaya dahil edildi.

Araştırmaya uygun 183 hasta tespit edilerek dosya bilgileri incelendi. Hastaların hepsine $50 \mathrm{mg} /$ $\mathrm{m} 2$ dozunda tek doz MTX yapıldı. Hastalar, 1-4-7 gün B-hCG değerlerine göre takip edilip 4.gün ile 7.gün B-hCG düzeyleri arasında $\% 15$ 'ten fazla dü- şüş gösteren hastalar başarılı kabul edilip haftalık B-hCG kontrolüne çağrıldı. Tedavinin herhangi bir aşamasında akut batın bulguları gelişip, hemodinamisi bozulan hastalar cerrahiye alınd1. Beta hCG düzeyi 4.gün ile 7.gün arasında \%15'ten az düşme gösteren hastalar başarısız kabul edilip 2.doz MTX yapildi.

Verilerin analizinde SPSS versiyon 15.0 programından yararlanıldı. Değişkenlerin normal dağılıma uygunluğu histogram grafikleri ve Kolmogorov-Smirnov testi ile incelendi. Tanımlayıc1 analizler sunulurken ortalama, standart sapma, ortanca değerler kullanılmıştır.

2x2 gözlerde Pearson Ki Kare ve Fisher's Exact Testleri ile karşılaştırıldı. 2x2'den fazla gözlerde bonferroni düzeltmesi ve post-hoc analizler uygulandı. İki değer arasındaki değişimin analizi için Wilcoxon Testi, gruplar arasında ölçümsel verilerin değişiminin analizi için tekrarlayan ölçümler varyans analizi kullanıldı. Duyarlılık (sensitivite), özgüllük (spesifite), pozitif prediktif değer (PPD) ve negatif prediktif değer (NPD) ile sunuldu.

Eşik değeri saptamak için ROC analizi uyguland1. P-değerinin 0.05 'in altında olduğu durumlar istatistiksel olarak anlamlı sonuçlar şeklinde değerlendirildi.

\section{BULGULAR}

Çalışmaya katılan 183 hastanın 142'sinde $(\% 77,60)$ ilk doz MTX ile başarıyla tedavisi sağlanırken 13 hasta akut batın gelişmesi üzerine cerrahi tedaviye alındı. Akut batın gelişmeyen ancak 4. ve 7. gün b-hcg değerlerinde yeterli düşme görülmeyip başarısız kabul edilen 28 hastaya ise ikinci doz MTX yapılmıştır. Bunların 26'sında $(\% 92,86)$ başarı sağlanmıştır. MTX ile başarılı şekilde tedavi edilen hastalar toplamda \%91,8 (168/183) olarak tespit edilmiştir (Şekil 1).

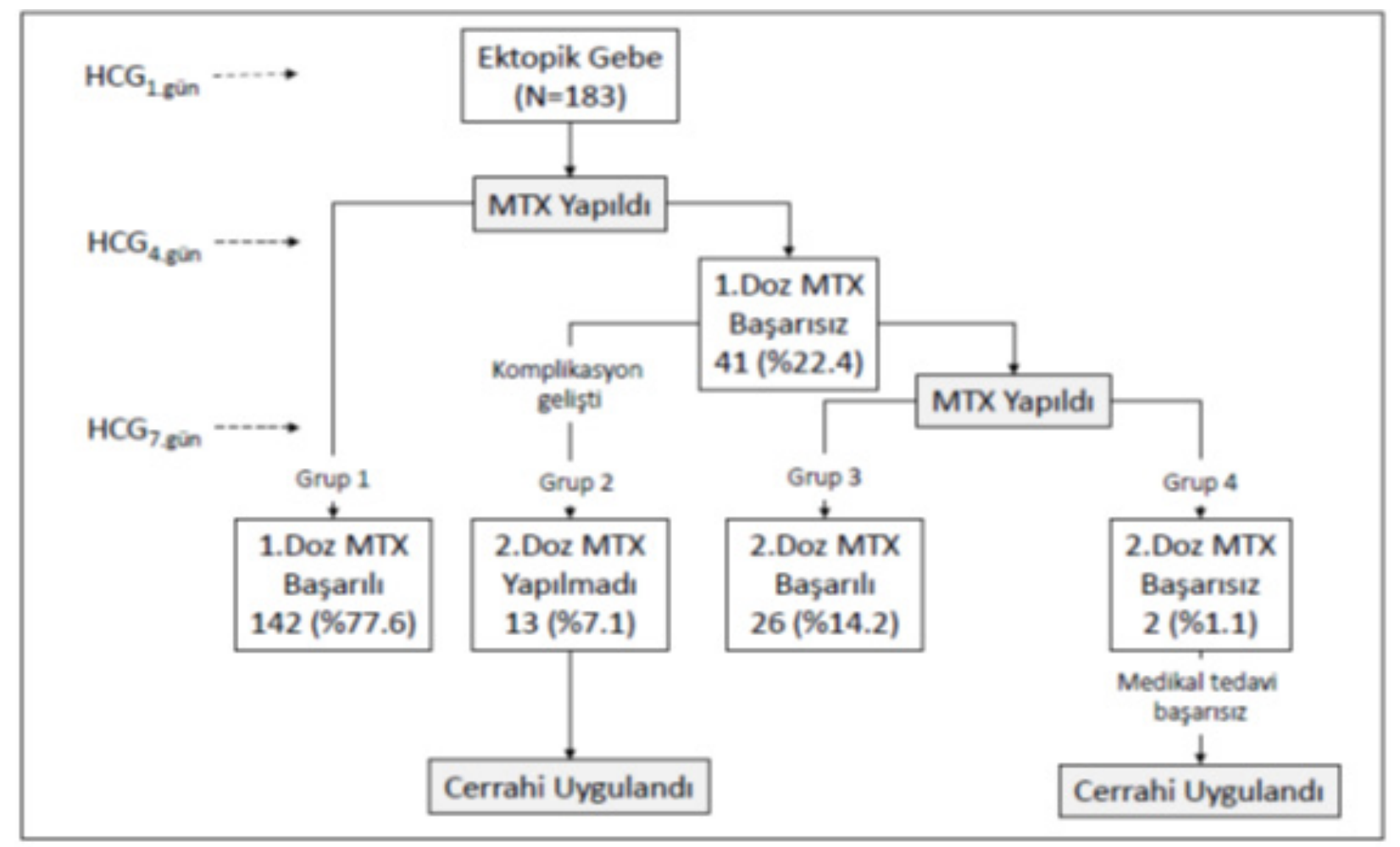

Şekil 1: Hastalara MTX uygulama ve başarı oranları. 
Hastaların 1. gün, 4. gün ve 7. gün B-hCG değerlerindeki değişim gruplar arasında karşıllaştırıldığında anlamlı değişimler olduğu görülmüștür. Grup 1 hastaların 1. gün $\mathrm{B}-\mathrm{hCG}$ medyan değeri $(762,0)$ grup 2 hastaların medyan değeri $(4277,0)$ ve grup 3 hastların medyan değerine göre $(2966,0)$ daha düşük bulunmuştur $(\mathrm{p}<0,001)$. Grup 1 hastaların 4. gün B-hCG medyan değeri $(484,5)$ grup 2 hastaların medyan değeri $(6207,5)$ ve grup 3 hastaların medyan değerine göre $(3519,5)$ daha düşük bulunmuştur $(\mathrm{p}<0,001)$. Benzer şekilde grup 1 hastaların 7. gün B-hCG medyan değeri $(232,0)$ grup 2 hastaların medyan değeri $(4931,0)$ ve grup 3 hastaların medyan değerine göre $(3821,0)$ daha düşük bulunmuştur $(p<0,001)$. Gruplar içinde günlere göre $\mathrm{B}-\mathrm{hCG}$ değerleri incelendiğinde; grup 1 hastaların 1-4 gün arası B-hCG değerinde anlamlı azalma olurken, grup 2 hastalarda ise 1-4 gün aras1 BHCG değerinde anlamlı artış olduğu gözlenmiştir $(\mathrm{p}<0,05)$ (Tablo 1).

1. gün B-hCG değeri 2000 altı olan hastalar ile 2000 ve üstü olanların tek doz MTX ile başarı oranları incelendiğinde; 1 . gün B-hCG değeri 2000 altı olanların tek doz MTX ile başarı oran1 $(\% 89,47)$, 2000 ve üzeri olanlara göre $(\% 57,97)$ daha yüksek olduğu görülmüştür $(\mathrm{p}<0,001)$ (Tablo 3 ).

1.gün B-hCG değeri 4000 altı olan hastalar ile 4000 ve üzeri olanların MTX ile toplam başarı oranları karşılaştırıldığında; 1. gün B-hCG değeri 4000 altı olanların toplamda başarı oranı $(\% 95,95), 4000$ ve üzeri olanlara göre $(\% 74,29)$ daha yüksek bulunmuştur $(\mathrm{p}<0,001)$ (Tablo 4).

Tablo 1: Hastaların 1. gün, 4. gün ve 7. gün B-hcg değerlerindeki değişimin gruplar arasında karşılaştırılması.

\begin{tabular}{|c|c|c|c|c|c|c|c|c|c|}
\hline & \multicolumn{2}{|c|}{$\begin{array}{l}\text { (Grup 1) } \\
\text { 1. doz MTX } \\
\text { başarılı }\end{array}$} & \multicolumn{2}{|c|}{$\begin{array}{c}\text { (Grup 2) } \\
\text { 1. doz MTX başarısız } \\
\text { 2. doz MTX yapılmadı }\end{array}$} & \multicolumn{2}{|c|}{$\begin{array}{l}\text { (Grup 3) } \\
\begin{array}{l}\text { 2. doz MTX } \\
\text { başarılı }\end{array} \\
\end{array}$} & \multicolumn{2}{|c|}{$\begin{array}{c}\text { (Grup 4) } \\
\begin{array}{c}\text { 2. doz MTX } \\
\text { başarısız }\end{array} \\
\end{array}$} & \multirow[t]{2}{*}{$\mathbf{P}$} \\
\hline & Medyan & \%95 G.A. & Medyan & \%95 G.A. & Medyan & \%95 G.A. & Medyan & \%95 G.A. & \\
\hline 1.GÜN & 762,0 & $(597,0-998,0)$ & 4277,0 & $(2254,0-6867,0)$ & 2966,0 & $(2027,0-3368,0)$ & 3092,0 & $(513,0-5671,0)$ & $<0,001$ \\
\hline 4.GÜN & $484,5^{1}$ & $(350,0-650,0)$ & $6207,5^{1}$ & $(3478,0-9763,0)$ & $3519,5^{1}$ & $(2050,0-5943,0)$ & 4531,5 & $(612,0-8451,0)$ & $<0,001$ \\
\hline 7.GÜN & $232,0^{2}$ & $(156,0-343,0)$ & $4931,0^{2}$ & $(3958,0-9517,0)$ & 3821,0 & $(2528,0-5337,0)$ & 4104,0 & $(1129,0-7079,0)$ & $<0,001$ \\
\hline
\end{tabular}

Tablo 2: 1. Gün B-hCG değer aralıklarına göre hasta gruplarının dağılımı.

\begin{tabular}{|c|c|c|c|c|c|c|c|c|c|c|c|c|c|}
\hline \multirow[t]{2}{*}{ B-hCG değeri } & \multicolumn{2}{|c|}{$\begin{array}{l}\text { (Grup 1) } \\
\text { 1. doz MTX } \\
\text { başarılı }\end{array}$} & \multicolumn{2}{|c|}{$\begin{array}{l}\text { (Grup 3) } \\
\begin{array}{l}\text { 2. doz MTX } \\
\text { başarılı }\end{array}\end{array}$} & \multicolumn{2}{|c|}{$\begin{array}{c}\text { (Grup 1+3) } \\
\text { Toplam } \\
\text { Başarı }\end{array}$} & \multicolumn{2}{|c|}{$\begin{array}{c}\text { (Grup 2) } \\
\text { 1. doz MTX } \\
\text { başarısız } \\
\text { 2. doz MTX } \\
\text { yapılmadı }\end{array}$} & \multicolumn{2}{|c|}{$\begin{array}{l}\text { (Grup 4) } \\
\begin{array}{l}\text { 2. doz MTX } \\
\text { başarısız }\end{array}\end{array}$} & \multicolumn{2}{|c|}{$\begin{array}{c}\text { (Grup 2+4) } \\
\text { Toplam } \\
\text { Başarısızlık }\end{array}$} & \multirow[t]{2}{*}{$\begin{array}{c}\text { Toplam } \\
\text { hasta } \\
\text { sayısı }\end{array}$} \\
\hline & $\mathbf{n}$ & $\%$ & $\mathbf{n}$ & $\%$ & $\mathbf{n}$ & $\%$ & $\mathbf{n}$ & $\%$ & $\mathbf{n}$ & $\%$ & $\mathbf{n}$ & $\%$ & \\
\hline$<499$ & 52 & $(92,85)$ & 3 & $(5,35)$ & 55 & $(98,21)$ & 1 & $(1,78)$ & 0 & $(, 00)$ & 1 & $(1,78)$ & 56 \\
\hline 500-999 & 31 & $(83,78)$ & 3 & $(8,10)$ & 34 & $(91,89)$ & 2 & $(5,40)$ & 1 & $(2,70)$ & 3 & $(8,10)$ & 37 \\
\hline 1000-1499 & 10 & $(83,33)$ & 2 & $(16,66)$ & 12 & $(100)$ & 0 & $(, 00)$ & 0 & $(, 00)$ & 0 & $(, 00)$ & 12 \\
\hline 1500-1999 & 9 & $(100)$ & 0 & $(, 00)$ & 9 & $(100)$ & 0 & $(, 00)$ & 0 & $(, 00)$ & 0 & $(, 00)$ & 9 \\
\hline 2000-2999 & 12 & $(66,66)$ & 5 & $(27,77)$ & 17 & $(94,44)$ & 1 & $(5,55)$ & 0 & $(, 00)$ & 1 & $(5,55)$ & 18 \\
\hline 3000-3999 & 9 & $(56,25)$ & 6 & $(37,50)$ & 15 & $(93,75)$ & 1 & $(6,25)$ & 0 & $(, 00)$ & 1 & $(6,25)$ & 16 \\
\hline 4000-4999 & 8 & $(80,00)$ & 0 & $(, 00)$ & 8 & $(80,00)$ & 2 & $(20,00)$ & 0 & $(, 00)$ & 2 & $(20,00)$ & 10 \\
\hline$>5000$ & 11 & $(44,00)$ & 7 & $(28,00)$ & 18 & $(72,00)$ & 6 & $(24,00)$ & 1 & $(4,00)$ & 7 & $(28,00)$ & 25 \\
\hline Toplam & 142 & $(77,59)$ & 26 & $(14,20)$ & 168 & $(91,80)$ & 13 & $(7,10)$ & 2 & $(1,09)$ & 15 & $(8,19)$ & 183 \\
\hline
\end{tabular}

${ }^{1}$ Ki-Kare Testi

Tablo 3: 1. gün BHCG değeri 2000 altı ve üstü olanların tek doz MTX ile başarı oranları.

\begin{tabular}{|c|c|c|c|c|c|c|}
\hline & & \multicolumn{4}{|c|}{ Tek doz MTX ile başarı } & \multirow{3}{*}{$\mathbf{p}^{1}$} \\
\hline & & \multicolumn{2}{|c|}{$\begin{array}{l}\text { Başarilı } \\
\text { (Grup 1) }\end{array}$} & \multicolumn{2}{|c|}{$\underset{\text { (Grup 2+3+4) }}{\text { Başarısız }}$} & \\
\hline & & $\mathbf{n}$ & $\%$ & $\mathbf{n}$ & $\%$ & \\
\hline \multirow{2}{*}{ 1. Gün B-hCG } & 2000 altı & 102 & $(89,47)$ & 12 & $(10,53)$ & \multirow{2}{*}{$<0,001$} \\
\hline & 2000 ve üzeri & 40 & $(57,97)$ & 29 & $(42,03)$ & \\
\hline
\end{tabular}

1 Ki-Kare Testi

Tablo 4: 1. gün B-hCG değeri 4000 altı olan hastalar ile 4000 ve üzeri olanların MTX ile toplam başarı oranları.

\begin{tabular}{|c|c|c|c|c|c|c|}
\hline & & \multicolumn{4}{|c|}{ MTX ile Toplam başarı } & \multirow{3}{*}{$\mathbf{p}^{1}$} \\
\hline & & \multicolumn{2}{|c|}{$\begin{array}{c}\text { Başarılı } \\
\text { (Grup 1+3) }\end{array}$} & \multicolumn{2}{|c|}{$\begin{array}{c}\text { Başarısıı } \\
\text { (Grup 2+4) }\end{array}$} & \\
\hline & & $\mathbf{n}$ & $\%$ & $\mathbf{n}$ & $\%$ & \\
\hline \multirow{2}{*}{ 1. Gün BHCG } & 4000 altı & 142 & $(95,95)$ & 6 & $(4,05)$ & \multirow{2}{*}{$<0,001$} \\
\hline & 4000 ve üzeri & 26 & $(74,29)$ & 9 & $(25,71)$ & \\
\hline
\end{tabular}

${ }^{1} \mathrm{Ki}-$ Kare Testi 
Hastaların başlangıç B-hCG değeri ile 4. Gün değerindeki değişikliğin başarıya etkisinin tespiti için ROC eğrisi çizildi ve eşik değer olarak $\% 10$ azalma görüldü. Eşik değer \%10 azalma alındığında duyarlılık \%74,60, özgüllük \%85,00, PPD \%94,60 ve NPD \%48,60 olarak bulundu.

\section{TARTIŞMA}

Çalışmamız, literatüre bakıldığında MTX ile başarı oranlarının bakıldığ lu çıkmıştır (5-11). Çalışmamızda tek doz MTX ile \%77,60 (142/183) olan başarı oranı, ikinci doz MTX ile beraber hastaların \%91,8'inde (168/183) başarılı olduğu tespit edilmiştir. Hırvatistan'da yapılan bir çalışmada, tek doz MTX ile başarı oranı $\% 68$ bulunurken, ikinci doz MTX sonrası başarı oranı \%91 bulunmuş ve çalışmamız ile uyumlu görülmüsşür (11).

Başlangıç B-hCG seviyelerine göre MTX tedavisinin başarı oranları incelendiğinde B-hCG seviyesi arttıkça başarı oranı düşüp hastaların ek doz MTX ihtiyaçları ve cerrahi ihtiyaçlarının arttığı izlenmiştir (Tablo 2). Her ne kadar başlangıç B-hCG seviyesi düşük olunca da hastaların cerrahi tedaviye gitme ihtimali olsa da bu oran başlangıç B-hCG düzeyi arttıkça istatistiksel olarak anlamlı olacak şekilde artmış ve literatür ile uyumlu görülmüştür (12).

B-hCG seviyelerine göre MTX etkinliğine bakılan benzer bir çalışmada başlangıç B-hCG seviyesi için cut-off $1790 \mathrm{mlU} / \mathrm{mL}$ bulunmuştur (7). Başka bir çalışmada ise başlangıç B-hCG seviyesi $2678 \mathrm{mlU} / \mathrm{mL}$ üzerinde olan hastalarda tek doz MTX ile başarısız tedavi riski 8.45 kat daha fazla bulunmuştur (10). Bizim çalışmamız da B-hCG değeri 2000 altında olan hastalarda tek doz MTX ile \%89,47 başarılı olunurken, 2000 ve üzerindeki hastalarda tek doz MTX ile başarı oranı \%57,97 bulunmuştur. Yine başlangıç B-hCG değeri 4000 ve üzerinde olan hastalarda MTX tedavisiyle başarısız olma riski B-hCG değeri 4000 altında olan hastalara göre 6.34 kat daha fazla bulunmuştur.

MTX tedavisinin başarısını göstermek amacıyla en çok kullanılan kriter 4.gün ile 7.gün B-hCG değerleri arasında \%15'ten fazla düşüş olmasıdır. Çoğu klinikte medikal tedavi verilen ektopik gebelikler, bu 7 günlük süre boyunca hastanede yatırılarak takip edilmektedir. Bu durum, klinisyenleri farklı kriterler bulma arayışına sokmuştur. Bu amaçla üzerinde en çok araştırma yapılan yöntem 1 . gün ile 4. gün B-hCG düzeyindeki düșme oranıdır. Literatürü incelediğimizde, çalışmalarda çelişkili sonuçlar olduğu görüldü. 2006 yılında yapılan bir çalışmada (13) 1-4 .gün B-hCG değişikliğine göre başarı durumunun öngörülemeyeceği belirtilse de sonrasında yapılan çalışmalarda umut vadeden sonuçlar bulunmuştur (14-17). Nguyen ve ark. yaptığ1 çalışmada 4. gün B-hCG değerinde başlangıç değerine göre düşme olması durumunda başarı oranı $\% 100$ bulunurken, artma olması durumunda başarı oranı \%61 olarak raporlanmıştır (14). Skubisz ve ark. yaptığ 1 başka bir çalışmada ise 4.gün değerinde başlangıç değerine göre düşme olması durumunda $\% 88$ başarıl1, yükselme olması durumunda ise $\% 42$ başarılı olduğu belirtilmiştir (15). Türkiye'de yapılan bir çalışmada da 4.gün değerinde düşme olması tedavinin başarılı olduğunu gösteren en önemli kriter olarak gösterilmiştir (16). Bizim çalışmamızda 4.gün B-hCG seviyesi başlangıç değerine göre $\% 10$ ve üzerinde düşme görülen hastalarda başarı oranı $\% 94,6$ bulunurken; daha az oranda düşme görülen hastalarda başarı oranı sadece \%48,6 bulunmuştur. Beta hCG'nin 4.gündeki düşme yüzdesi artıkça pozitif prediktif değeri artarken, testin duyarlılığ 1 azalmıştır. Benzer olarak 4. günde $\% 26$ 'den fazla azalmayı cut off olarak alan bir çalışmada da başarı oran $\% 100$ bulunmuştur (17).

\section{SONUÇ}

Methotrexate iyi seçilen ektopik gebelik olgularında yüksek başarı oranına sahip, non-invaziv bir tedavi yöntemidir. Başlangıç B-hCG değeri arttıkça başarı oranı düşse de bizim çalışmamızda B-hCG düzeyi $5000 \mathrm{mlU} / \mathrm{mL}$ üstündeki hastalarda bile \%72 oranında başarılı olduğu görülmüştür. MTX için kontrendikasyonu olmayan, hemodinamisi stabil hastalarda öncelikle MTX tedavisinin seçilmesi gerektiğini düşünmekteyiz. 1-4. gün B-hCG seviyesindeki $\% 10$ ve üzerindeki düşüş tedavinin başarılı olduğuyla ilgili yüksek prediktif $(\% 94,6)$ bir değer verse de , \%10'dan az düşüşlerde de \%48,6 oranında başarılı olmasından dolayı, 4-7 gün B-hCG değişikliğinin başarı kriteri olarak kullanılması daha kullanışl1 görünmektedir.

\section{KAYNAKLAR}

1. 1. Tamay AG, Yıldırım Y, Koltan SO, Adiyeke M, Koyuncu FM. Ektopik gebelik tedavisi: 74 olgunun retrospektif değerlendirilmesi Ist Tip Fak Derg 2011; 74:2

2. Bouyer J, Coste J, Fernandez H, et al. Sites of ectopic pregnancy: a 10 year population-based study of 1800 cases. Hum Reprod 2002; 17:3224.

3. Lozeau AM, Potter B. Diagnosis and management of ectopic pregnancy. Am Fam Physician 2005;72(9):1707-1714.

4. Gözüküçük M, Kahraman K, Çetinkaya E, Sezinkurt E, Sönmezer M, Berker B, Dökmeci F: Ektopik Gebelik Olgularında Tanı Kriterlerinin Tedavi Seçimine Etkisi; Ankara Üniversitesi Tıp Fakültesi Mecmuası 2009, 62(3)

5. Thia E W H, Loi K, Wang JJ, Siow A. Methotrexate treatment for ectopic pregnancy at the KK Women's and Children's Hospital, Singapore. Singapore Med J 2009; 50 : 1058.

6. Jurkovic D, Memtsa M, Sawyer E, Donaldson AN, Jamil A Schramm K, Sana Y, Otify M, Farahani L, Nunes N, Ambler G4, Ross JA2. Single-dose systemic methotrexate vs expectant management for treatment of tubalectopic pregnancy: aplacebo-controlled randomized trial. Ultrasound Obstet Gynecol. 2017 Feb;49(2):171-176.

7. Nowak-Markwitz E, Michalak M, Olejnik M, Spaczynski M. Cutoff value of human chorionic gonadotropin in relation to the number of methotrexate cycles in the successful treatment of ectopic pregnancy. Fertil Steril. 2009 Oct;92(4):1203-7.

8. Erdem M, Erdem A, Arslan M, Oç A, Biberoğlu K, Gürsoy $R$. Single-dose methotrexate for the treatment of unruptured ectopic pregnancy. Arch Gynecol Obstet. 2004 Dec;270(4):201-4. Еpub 2003 Sep 3. 
9. Yıldırım G, Güngördük K, Aktaş FN, Ülker V, Sudolmuş S, Tekirda $\breve{g}$ AI. Ektopik Gebelik Tedavisinde Tek Doz Metotreksat: 85 Olgunun Değerlendirilmesi TJOD 2007; 4: 68-71.

10. Tas EE, Akcay GF, Avsar AF. Single-dose methotrexate for the treatment of ectopic pregnancy: Our experience from 2010 to 2015: Pak J Med Sci. 2017 Jan-Feb;33(1):13-17.

11. Kasum M, Oresković S, Simunić V, Jezek D, Tomić V, Tomić J, Gall V, Mihaljević S. Treatment of ectopic pregnancy with methotrexate. Acta Clin Croat. 2012 Dec;51(4):543-8.

12. Menon S, Colins J, Barnhart KT. Establishing a human chorionic gonadotropin cutoff to guide methotrexate treatment of ectopic pregnancy: a systematic review. Fertil Steril. 2007 Mar;87(3):481-4. Epub 2006 Dec 14.

13. Gabbur N, Sherer DM, Hellmann M, Abdelmalek E, Phillip P, Abulafia O. Do serum beta-human chorionic gonadotropin levels on day 4 following methotrexate treatment of patients with ectopic pregnancy predict successful single-dose therapy? Am J Perinatol. 2006 Apr;23(3):193-6. Epub 2006 Mar 29.

14. Nguyen Q, Kapitz M, Downes K, Silva C. Are early human chorionic gonadotropin levels after methotrexate therapy a predictor of response in ectopic pregnancy? Am J Obstet Gynecol. 2010 Jun;202(6):630.e1-5.

15. Skubisz MM, Li J, Wallace EM, Tong S. Decline in $\beta h C G$ levels between days 0 and 4 after a single dose of methotrexate for ectopic pregnancy predicts treatment success: a retrospective cohort study. BJOG. 2011 Dec;118(13):1665-8.

16. Celik E, Türkçüoğlu I, Karaer A, Kırıcı P, Eraslan S Assessment of early decline in the percentage of $\beta$ - $h C G$ values between days 0 and 4 after methotrexate therapy in ectopic pregnancy for the prediction of treatment success. J Turk Ger Gynecol Assoc. 2013 Sep 1;14(3):125-9.

17. Ozyurek ES, Akmut E, Kaya E, Akca A, Akbayır O. Predictors of failure of the commonly used single-dose methotrexate protocol for treating tubal ectopic pregnancies. Taiwan J Obstet Gynecol. 2017 Dec;56(6):755-760. 